\section{Exploring the world using the sense of smell}

Irmina Wojciechowska, Aleksandra Wojciechowska, Karolina Wieszczycka

DOI: $10.24131 / 3247.170106$

\section{Summary:}

The sense of smell, also known as olfaction, is one of the chemical human senses. This means that sensory stimuli are received by the human body through contact with chemicals. The smell becomes recognizable when the responsible chemical meets certain requirements e.g. it becomes volatile. Chemicals with similar structures can make an impression of radically different aromas. A slight change in the spatial structure or removing one atom from a molecule may be enough to make an odour pleasant. Sometimes, the concentration of the substance decides on the nature of the smell - the same chemical compound can make evoke the smell of flowers or of rotting flesh. As it turns out, the sense of smell also plays an important role in the sense of taste.

Key words: fragrances, organic chemistry, human senses, smell

received: 14.07.2016; accepted: 27.01.2017; published: 18.04.2017

Irmina Wojciechowska, M.Sc., Eng.: Faculty of Chemica Technology, Poznań University of Technology

Aleksandra Wojciechowska, M.A.: Faculty of Chemical Technology, Poznań University of Technology

Karolina Wieszczycka, Ph.D., D.Sci,, Eng.: Faculty of Chemical Technology, Poznań University of Technology
It is hard to imagine a world without smells. It's not just about the inability to enjoy the aromas of freshly ground coffee, English roses or the earth after rain. Impairment of the sense of smell, called anosmia, affects even as much as $6 \%$ of human population and leads not just to the impoverishment of smell sensations, but also to the disturbance of taste perception and... recognizing emotions (Croy et al., 2014). The goal of this paper is share basic information about aroma compounds. In this article, you will find information on how the human body copes with smells and how the chemical structures of aroma compounds influence the type of smell sensation. We will hereby present and illustrate differences in the chemical structure of some organic compounds that may seem to be irrelevant, but actually influence their properties in a significant way.

The sense of smell is one of the most primitive ways of perceiving the surrounding world. This may be associated with predators hunting for their prey and may seem to be insignificant for modern humans. Nothing could be more wrong!

Fig. 1. Aroma compound structures with exemplary origins: a - perfume component: gardenia flower aroma, b - freshly brewed coffee aroma Photo: Irmina Wojciechowska

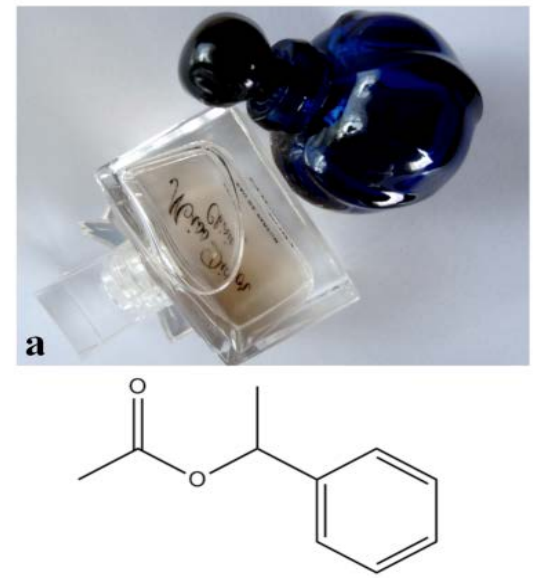

1-phenylethyl acetate
Smell is associated with a human being from the first moments of our lives. The smell of a mother's body is one of the first recognized by an infant, and so is the smell of food and the baby's environment. This is actually a period of life when odors start to play an important role in creating memories and emotions, which is attributed to the proximity of the olfactory system and the limbic system in the human brain. Each of us can name at least a few smells that connote good - or to the contrary, bring up bad - memories. Sometimes a single smell can suddenly recall completely forgotten emotions and memories. Research conducted on a group of volunteers confirm the hypothesis that the sense of smell serves as a communication channel between people - in this original way, we can sense each other's fear, dismay or disgust and the alarm of others in our area about a serious threat (De Groot et al., 2012). In 2004, the Noble Price was awarded to Linda B. Buck and Richard Alex for their research, which proved that as much as $2 \%$ of the human genome is involved in coding smell receptors, also known as odorant receptors, over 
half of which are active genes. This fact proves just how important smell stimulants are to people (Nobel Media $A B, 2004)$. The desire to modify the smell of one's own body is nothing new. What once served as a camouflage and a way to blend into the crowd, has become a way to stand out. We mask our individual smell to become someone else, to highlight our individuality and expose particular features of our personality. It is impossible to provide a single reason as to why a sensual fame fatale should smell of ambergris and musk, and a successful man of citrus and cedar, just as there is no way to assign certain smells to universal labels to which everyone with a working nose can agree. There are as many opinions about smells as people; however, it seems obvious that a person smelling nice to us will generate more sympathy. But here comes the hippocampus again, demanding its weighty role, controlling our emotions and memories (Brud and Konopacka-Brud, 2009).

Defining the nature of smell is not an easy task; therefore theories on how we identify smells have frequently divided scientists into two camps.

We can draw one conclusion from the explanations presented in Wright's vibration theory (Wright, 1961) or Amoore's stereochemical theory (Amoore, 1952): it is not just the 3-D structure of a compound that determines the way something smells, but also the presence of certain functional groups.

The smells that we detect are built from chemical compounds. To receive aroma stimulants, a compound needs to be volatile - this is a necessary condition. The presence of osmophores, functional groups present in aroma compounds, is also important. Usually, the compounds that contain functional groups with build-in oxygen atoms, such as hydroxyl, ether, aldehyde, ester or ketone groups, tend to create pleasant sensory impressions, unlike the groups with built-in sulfur or nitrogen atoms, such as the thiol group. However, there
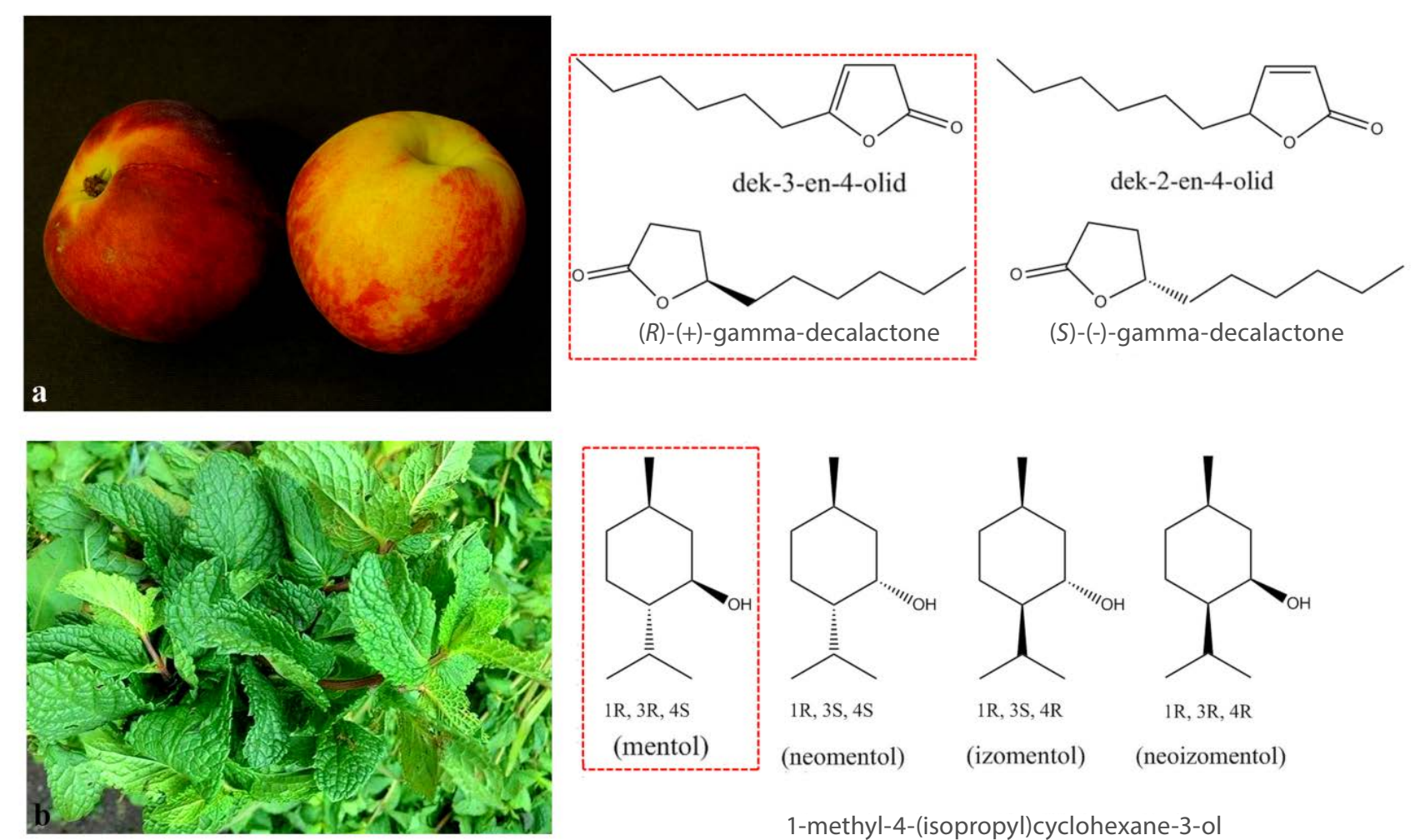

$1 \mathrm{R}, 3 \mathrm{~S}, 4 \mathrm{~S}$

$1 \mathrm{R}, 3 \mathrm{~S}, 4 \mathrm{R}$

$1 \mathrm{R}, 3 \mathrm{R}, 4 \mathrm{R}$

(neomentol)

(izomentol)

(neoizomentol)

1-methyl-4-(isopropyl)cyclohexane-3-ol

Fig. 2. The connection between isomerism and the chemical properties of organic compounds: structures colored red contain the smell of peach (a) and mint (b)

Photo: Irmina Wojciechowska, Aleksandra Wojciechowska

are some exceptions to this rule, for example furfuryl mercaptan (Fig. 1), which contains a thiol group, but is responsible for the delightful smell of freshly brewed coffee (Sunarharum et al., 2014; Mitka and Staryńska, 2012; Mills, 1995).

Any person working with the chemistry of smells can sometimes predict the aroma of a compound just from its structure - the presence of aroma rings, unsaturated bonds, or heteroatoms. This has a huge impact on designing new aromas and on the production of compounds that can replace natural scents that are difficult to acquire. A good example is synthetic vanillin, which has excellent productivity and successfully replaces traditional natural vanillin acquired from a $\mathrm{Va}$ nilia planifolia plant (Turin and Yoshii, 2002).

Popular and cheap nitro-musk produced on a large scale for the cosmetics industry replaces natural musk that costs a fortune. This type of progress must be enjoyed by Siberian musk deer, as the production of this beloved scent has caused their destruction since the time 
when poachers were searching for this lucrative source of income. It is also important to mention the group of fatty aldehydes containing from 10 up to 12 carbon atoms in their structure; without them, the world-famous fragrance composition of Chanel No. 5 could have never been developed (Mitka and Staryńska, 2012).

It also happens that traditional chemical synthesis cannot meet the demands of the consumer market. This is when biotechnology comes into play, as in the case of gamma-decalactone, a cyclic ester with an annual production of several hundred tons. As a result of chemical synthesis, we can obtain a racemic mixture of products, such as $R$ and $S$ enantiomers of gamma-decalactone. The first has the recognizable aroma of peach and the second one - of mango (Fig. 2). To avoid the creation of recemat, the desired product is obtained on an industrial scale from Yarrowia lipolytica yeasts (Krzyczkowska et al., 2009).
Gamma-decalactone is not the only example of how much influence the 3-D structure of compounds has on smell sensations. A widely known aroma compound is menthol, actually $(1 R, 3 R, 4 S)$-1-methyl-4-(isopropyl) cyclohexane-3-ol. Even though it has three isomers, only the levorotatory menthol is responsible for the distinctive, mint taste and smell and its refreshing cooling effect. The remaining isomers do not have these properties, even though the structure differences between them are slight (Fig. 2).

Gardenol, also known as 1-phenylethyl acetate, has a distinct smell, described as green, sweet and flowery, bringing to mind gardenia flowers (hence its popular name). This compound is found, for instance, in La Panthere, the elegant fragrance composition from the Cartier fashion house. On the other hand, its constitutional isomer 2-phenylethyl acetate, smells like ripe, honey peach and apricot (Fig. 1). Such examples can be

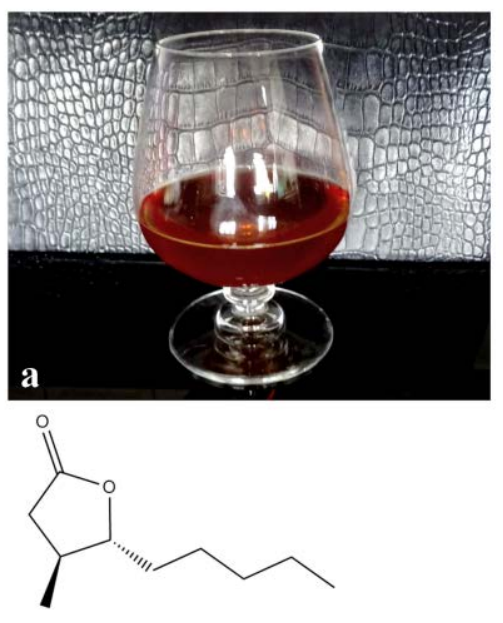

(-)trans-Cognac-lactone
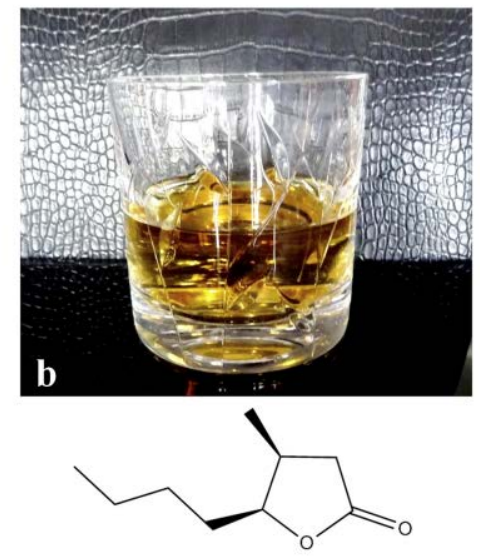

(-)trans-Whiskey-lactone
Fig. 3. A small difference in the compound structure results not just in a different smell, but also taste, which is noticeable, for example: in the compounds that are the aroma components of cognac (a) and whiskey (b) Photo: Maria Teresa A. Reis multiplied. All you have to do is to move an unsaturated bond in a compound of dec-3-en-4-olide to change the pleasant fruity smell into a distinct fungal aroma typical for dec-2-en-4-olide (Brud and Konopacka-Brud, 2009).

There is also the interesting case of eliminating just one carbon atom from an alkyl substituent in a cyclical lactone ring. A compound containing an aliphatic string composed of 5 atoms of carbon in its structure was named cognac lactone, while the compound with one less carbon atom was named whiskey lactone (Fig 3 ). Both of these compounds are, of course, used to aromatize the respective alcohols from which they take their names (Krzyczkowska et al 2009).

The 3-D structure influences not only the type of smell our noses perceive, but also its intensity. It was determined that dextrorotatory nootkatone enantiomer, a grapefruit-like smelling compound, is a thousand times more detectible than its levorotatory isomer of the same aroma. This means that we are able to determine the smell of a dextrorotatory isomer as grapefruit-like at a thousand times lower concentration than in the case of its levorotatory enantiomer (Furusawa et al., 2005).

The dependence on concentration for determining the smell of a substance is a typical characteristic of aroma compounds. Usually, the higher the concentration of a compound, the more abhorrent is its smell. For example, isobutyric acid has a strong, piercing smell, but when diluted, it turns out to be pleasantly fruity; 2-methylbutyric acid changes its aroma from sharp, irritating and "cheesy" to pleasantly fruity; and isovaleric acid from cheesy and unpleasant to herbal with a hint of nut and coffee (Krzyczkowska et al., 2009). Even more surprising examples are skatole and indole, two products of the tryptophan metabolism: their high concentration is responsible for the smell of mammalian feces, but in lower concentrations, they release flowery aromas 


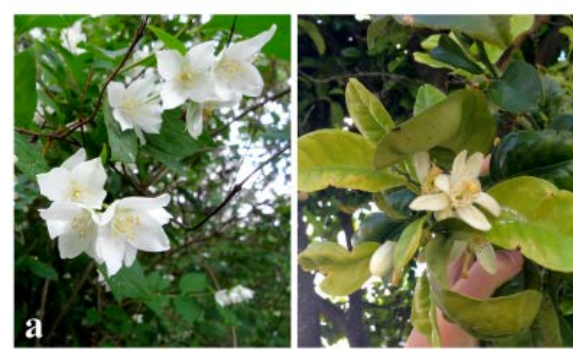

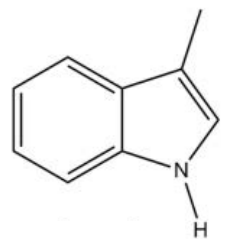

skatole

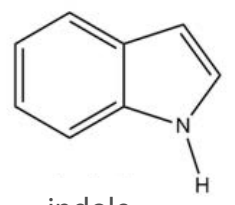

indole

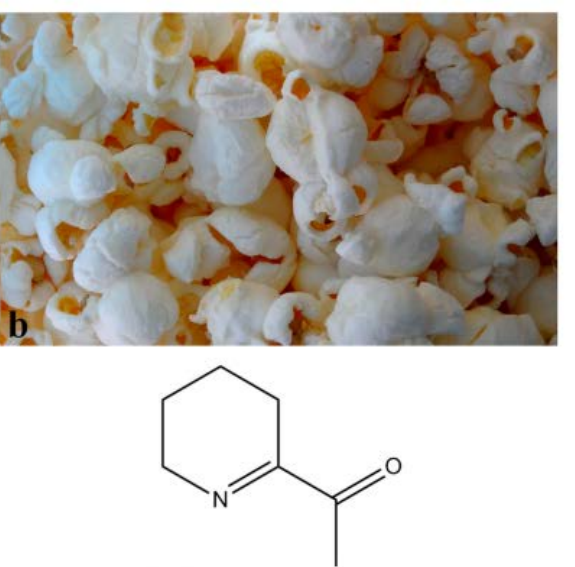

6-acetyl-1,2,3,4-tetrahydropyridine
Fig. 4. Skatole and indole at low concentrations smell like orange flowers and jasmine (a);

6-acetyl-1,2,3,4

tetrahydropyridine is responsible for the aroma of popcorn and fresh bread (b) Photo: Irmina Wojciechowska

(Fig. 4). Moreover, skatole is used to aromatize tobacco (Bera et al., 2014).

It is not always possible to get rid of an unpleasant smell by dilution. A good example is two biogenic amines, putrescine and cadaverine, also known as death aromas. These are products of amino acids, ornithine and lysine metabolism, respectively, and the first ones to be produced in a decomposing body after death. Their almost immediate appearance creates the opportunity for rescue dogs to quickly find bodies under the rubble of collapsed buildings. It is also important because, aside from their disgusting smell, these compounds - belonging to the ptomaine group, i.e. so called cadaverous poisons - are harmful to human health and toxic in high doses. Moreover, it is interesting to point out that putrescine is also responsible for common "morning breath" (Hussain et al., 2013).

The sense of smell is not the only chemical sense of a human being. In case of the sense of taste, we can talk of the high correlation between the structure of food compounds and the emotional assessment of the sen- sual sensations we perceive. Since 2015, a new developing science called neurogastronomy has been arousing the interest of many people. This field of science studies the connections between the functioning of human senses and perceived tastes. In other words, the light in a restaurant, the color of a plate or the texture of your meal each plays a key role in the perception of taste. The smell we receive is even more important (University of Kentucky, 2015).

The human nose serves several functions. Two of them constitute the subject of this article. The first one is to receive external stimulants, i.e. to examine the flow of information coming from the environment. The second function is related to sensing the smell of what we have inside our mouths, i.e. the perception of internal stimulants. Oral smell is stronger than the smells coming from the outside, so even a small concentration of aroma is enough to notice it. Some researches proved the hypothesis that we cannot properly assess the taste of a meal unless we can sense its aroma (Bałczewska, 2000). Without the ability to smell, some tastes become suppressed and are hard to recognize, while the others, such as, for example, the taste of chocolate, disappear altogether (Shepherd, 2015).

Shops selling bread take advantage of the phenomenon of the correlation between the senses of smell and taste and use a synthetic aroma compound called 6-acetyl-1,2,3,4-tetrahydropyridine (Fig. 4) to aromatize the air with the smell that recalls the smell of bread crust, fresh popcorn and crunchy buns to customers. This pleasant smell, which may have nothing in common with the actual quality of the particular bakery's products, recalls a taste that we know. We succumb to the emotional reaction to the smell, which allows us to sense the taste in a fuller and more pleasant way (Adams et al., 2004; Harrison and Dake, 2005).

A world without smells would be undoubtedly poor. Human emotions and memories, our communication and the expression of who we are and who we would like to be to others, would also be impoverished. Without the information sent by the sense of smell, we would ignore the dangers we face. The nature of smell itself is incredibly complex: from the mechanisms by which the human body receives smell signals ending with the structures of smell-stimulating chemical compounds themselves. In the end, it is difficult not to come to the conclusion that our lives would be significantly changed without smells; they are of great importance to us, since they help in perceiving the world that surrounds us.

\section{References}

Adams A, Tehrani KA, Kersiene M, De Kimpe N (2004). Detailed investigation of the production of the bread flavor component 6-acetyl-1,2,3,4-tetrahydropyridine in proline/1,3-dihydroxyacetone model systems. Journal of Agricultural and Food Chemistry. 18: 5685-5693.

Amoore JE (1952). The stereochemical specificities of human olfactory receptors. Perfumery \& Essential Oil. 43: 321-330.

Bera P, Kotamreddy JNR, Samanta T, Maiti, Mitra A (2014). Inter- 
-specific variation in headspace scent volatiles composition of four commercially cultivated jasmine flowers. Natural Product Research: Formerly Natural Product Letters. 29: 1328-1335.

Brud WS, Konopacka-Brud I (2009). Podstawy perfumerii. Historia, pochodzenie i zastosowania substancji zapachowych. MA Oficyna Wydawnicza.

Croy I, Nordin S, Hummel T (2014). Olfactory disorders and quality of life-an updated review. Chemical Senses. 39: 185-194.

De Groot JHB, Smeets MAM, Kaldewaij A, Duijndam MJA, Semin GR (2012). Chemosignals Communicate Human Emotions. Psychological Science, 11:1417-1424.

Furusawa M, Toshihiro H, Yoshiaki N, Yoshinori A (2005). Highly Efficient Production of Nootkatone, the Grapefruit Aroma from Valencene, by Biotransformation. Chemical and Pharmaceutical Bulletin. 11: 1513-1514.

Harrison T, Dake GR (2005). An Expeditious, High-Yielding Construction of the Food Aroma Compounds 6-Acetyl-1,2,3,4-tetrahydropyridine and 2-Acetyl-1-pyrroline. Journal of Organic Chemistry. 26: 10872-10874.

Hussain A, Saraiva LR, Ferrero DM, Ahuja G, Krishna VS, Liberles S, Korching S (2013). High-affinity olfactory receptor for the deathassociated odor cadaverine. Proceedings of the National Academy of Sciences of the United States of America. 48: 19579-19584.

Krzyczkowska J, Białecka-Florjańczyk E, Stolarzewicz I (2009). Biotechnologiczne metody otrzymywania substancji zapachowych. Żywność. Nauka. Technologia. Jakość. 64: 5-18.

Mills B (1995). Review of methods of odour control. Filtration \& Separation. 32: 146-152.

Mitka K, Staryńska J (2012). Synteza substancji zapachowych - pochodnych aldehydów. Czasopismo Techniczne Wydawnictwa Politechniki Krakowskiej. 109: 135-148.

Nobel Media AB (2004). The 2004 Nobel Prize in Physiology or Medicine to Richard Axel and Linda B. Buck. Nobelprize.org [artykuł]. Available at: http://www.nobelprize.org/nobel_prizes/medicine/laureates/2004/press.html. Accessed on: 25.04.2016.

Shepherd G (2015). Neuroenology: how the brain creates the taste of wine. Flavour. 4:19.

Sunarharum W, Wiliams D, Smyth H (2014). Complexity of coffee flavor: a compositional and sensory perspective. Food Research International. 62: 315-325.

Turin L, Yoshii F (2002). Structure-odor relations: a modern perspective. New York: Handbook of Olfaction and Gustation.

University of Kentucky (2015). Neurogastronomy: How our brains perceive the flavor of food. ScienceDaily [artykuł popularnonaukowy]. Available at www.sciencedaily.com/releases/2015/11/151118160600. htm. Accessed on: 25.04.2016.

Wright RH (1961). Odour and Molecular Wibration. Nature. 190: 1101-1102. 